Željko Jović ${ }^{\text {, Jelena Cvijović }}{ }^{2}$

${ }^{1}$ Medi Group, Milutina Milankovića 3, Belgrade, Serbia

${ }^{2}$ University of Belgrade, Faculty of Organizational Sciences, Serbia

\title{
Private Healthcare Institutions and Insurance Companies: from Cooperators to Market Competitors
}

UDC: 005.56:[61:368

334.722

DOI: 10.7595/management.fon.2015.0020

\begin{abstract}
The provision of adequate healthcare nowadays has a global character, so the implementation of efficient and well-formulated health reforms has become of serious importance. Among many contemporary trends in this area, there is a tendency of privatization of health care institutions and growth in private insurance premiums. This raises the necessity of developing a cooperation between private healthcare institutions and insurance companies in order to provide services of an improved quality. This paper emphasizes the extremes of their cooperation, moving from fully integrated systems towards competition over the market.The findings indicate that, due to the insufficient development of Serbian healthcare sector, their cooperation is so far not at a high level, which brings many issues into question and that should be legally better defined.
\end{abstract}

Keywords: Private healthcare institutions, insurance companies, relationship, cooperation, competition

\section{Introduction}

Globally observed, great emphasis is being put to the provision of health care, therefore, many countries tend to implement modern, efficient and well-formulated health policies (Echebiri, 2014).The implementation of such policies is influenced by macroeconomic, political and social factors (Savedoff, 2004; Gotsadze et al., 2005). The provision of adequate health care services to all members of the population at affordable prices is crucial for the health equity achievement and raising the quality of life (Carrin\& James, 2005; Yasar\&Ugurluoglu, 2011; Griffin et al., 2014). The functioning of the health care sector is evaluated by the way it manages to achieve those goals, as well as by its responsiveness to consumers' needs and provision of financial risk protection (Collins, 2006). As governments around the world are often not able to provide sufficient funds to finance health services (Scandinavian Care, 2006), funding from both public and private sources is necessary to improve a general health situation (Song \& Smith, 2007). Therefore, the main sources of health services financing are: taxes, budget revenues for prevention programs, social insurance and private contributions (including co-payments for public health services, fees for additional services and private insurance premiums) (Schaapveld\& Rhodes, 2004). For such reasons, private health care institutions and insurance companies pay more attention, especially in developing countries (Sekhri\&Savedoff, 2005). Besides funding reasons, there are other benefits of private health sector development. Well organized and developed private health markets protect consumers' rights and promote "the equity, affordability and access to health services" (Jost, 2001).Therefore, the privatization of health care institutions and the expansion of private insurance coverage need to be encouraged in order to enable an easier access to sufficient health care to the whole population and reduce social inequities. The necessity of formulation of partnerships between healthcare institutions and insurance companies is obvious in order to strengthen the competence of healthcare sector and share responsibility by this inter-sectorial cooperation (Raminashvili, 2014). This trend is especially evident in developed countries, although more and more developing countries are starting to follow, despite the economic and political restrictions (Kutzin, 2001). This appears to be also evident in Serbia, where partnerships of that type are emerging in the market. 


\section{Current trends in healthcare}

There are several very prominent trends that affect healthcare systems on national and global levels. The first one is reorganization of health care system, in a way which provides reducing of resources for its administration, encouraging the provision of high quality services at the least possible cost, expansion of the quantity of provided services and collection and distribution of funds (Murray \&Frenk, 2001; Johnston, 2004). In case of nationalized health systems, the government takes care of these issues, while in modernized systems, these tasks are delegated to healthcare institutions and insurance funds that operate at lower administrative costs and negotiate prices in a way consumers demand (Kotzian, 2008). So, reorganization of healthcare systems includes five imperatives:better performance through mergers, acquisitions and new partnerships; maintenance of cost competitiveness based on ability to provide value; demonstrated quality as part of the value challenge, an exceptional service as a key aspect of competitive advantage; real integration of all the subjects or parts of a system, not just their cooperation, etc. (Zuckerman, 2014).

The second trend is the expansion of private healthcare institutions, which is notable on a global level, as well as in Serbia. In Serbia, there is currently 1,553 registered private health institutions (not including pharmacies and dental offices), out of which 15 are general hospitals, 52 sare pecialized hospitals, 14 are health centers and 123 are polyclinics. Private health care institutions in Serbia are well-equipped; they have 35 scanners, 11 magnets, one device for radiotherapy, 700-800 ultrasounds, 30 mammography devices and 50 X-rays. They employ about 3,400 doctors of various specialties (Institute of Public Health of Serbia "Dr Milan Jovanović Batut",2013). The number of reported visits to private health care institutions in Belgrade was 479583 in 2012. Patients and corporate clients of private healthcare institutions paid approximately 95 million RSD during the same year, which amounts to nearly 200 Euros per capita that Serbian citizens paid for health services in the private sector (Institute of Public Health of Serbia "Dr Milan Jovanović Batut", 2012).

The next important trend is a movement toward an integrated, patient-focused health approach. Since consumers pay much attention to a qualitative dimension of healthcare services, they decide to either use public provider services, which are tax financed but which maintain a fixed quality, or a range of different private provider services of high quality. Their decisions depend not solely on variables such as sociodemographic characteristics, income and health situation, but also on the quality of treatments that the public sector provides. Some research results point out that there is a positive correlation between a lower public service quality (longer waiting times, above all) and a higher likability of turning to services of the private sector (Jofre-Bonet, 2000). This is especially the case in Serbia, where waiting lists for certain health treatments are extremely long. For example, around 10,000 patients are waiting for diagnostic methods, about 14,000 patients for orthopedic surgery, while the number of cardiac patients who require surgery is around 8,000 (Serbian Republic Health Insurance, 2013). By considering these data, as well as the tendency of continuous growth in the number of patients, the significance of private health care institutions is more than evident for the whole state, in addition to the importance of profit they bring to their owners.

Changes also occur in insurance companies and insurance services they offer. Globally observed, it is noted that the expansion of new insurance schemes will help reducing the health expenditures of individuals and households and enlarging the number of insured, as the lack of health insurance is directly associated with a limited access to medical services and worse health conditions (Smith, 2008; Borghi et al., 2008; Cannoodt, 2012). Ten insurance companies currently operate on the territory of the Republic of Serbia (among them some are owned by the insurance companies based abroad). Table 1 provides an overview of the market share of insurance companies by type of voluntary health insurance in 2013. Although Serbia has a long history of insurance business, the first private health insurance appeared in the 90s of the last century. The reason for this is primarily in the socio-political system that functioned in the former Yugoslavia, as well as in the organization of health sector during that period. Since then, voluntary health insurance sector in Serbia records a steady growth every year and the current situation can be seen in Table 2. It is estimated that, in the years to come, voluntary health insurance in Serbia will grow by $5 \%$ annually (about 30,000 premiums) (Delta Generali, 2012). Bearing in mind that the European average is $24 \%$ of new users of voluntary health insurance every year (Delta Generali, 2012), it can be concluded that many years will pass until Serbia reaches the European level. 
Table 1: Market share of insurance companies in Serbia(NBS, 2013).

\begin{tabular}{|l|l|l|}
\hline Insurance companies & $\begin{array}{c}\text { Total premium } \\
\text { (in 000 RSD) }\end{array}$ & $\begin{array}{c}\text { Market } \\
\text { share }\end{array}$ \\
\hline AMS & 28068 & $2.59 \%$ \\
AS & 750 & $0.07 \%$ \\
AXA & 389 & $0.04 \%$ \\
DDOR & 164033 & $15.14 \%$ \\
Delta Generali & 562949 & $51.97 \%$ \\
Dunav & 122314 & $11.29 \%$ \\
Globos & 946 & $0.09 \%$ \\
Takovo & 2355 & $0.22 \%$ \\
UNIQA & 158336 & $14.62 \%$ \\
Wiener & 43050 & $3.97 \%$ \\
TOTAL & $\mathbf{1 0 8 3 1 9 0}$ & $\mathbf{1 0 0}$ \\
\hline
\end{tabular}

Table 2: Overview of insurance according to the types of voluntary health insurance in 2013 (NBS, 2013)

\begin{tabular}{|c|c|c|c|}
\hline $\begin{array}{l}\text { Type of voluntary } \\
\text { health insurance }\end{array}$ & $\begin{array}{l}\text { Number of } \\
\text { companies }\end{array}$ & $\begin{array}{l}\text { Number of the } \\
\text { insured }\end{array}$ & $\begin{array}{l}\text { Total premium } \\
\text { (in } 000 \text { RSD) }\end{array}$ \\
\hline Parallel health insurance & 1250 & 3151 & 10209 \\
\hline Supplemental health insurance & 4189 & 621676 & 625136 \\
\hline Private health insurance & 189 & 3289 & 82404 \\
\hline $\begin{array}{l}\text { All other voluntary health insurance } \\
\text { (combinations of travel insurance during } \\
\text { staying abroad) types }\end{array}$ & 13681 & 25116 & 365441 \\
\hline TOTAL & 19309 & 653232 & 1083190 \\
\hline
\end{tabular}

On the basis of presented data, it can be concluded that only $6 \%$ of the Serbian population uses some form of voluntary health insurance, while a great portion of it goes to travel health insurance, which is mandatory for citizens when traveling abroad.The main reasons why health insurance has not grown in the past 20 years are:

- The low level of life standard;

- Lack of sufficient tax incentives for voluntary health insurance premiums;

- Lack of education of the population on the functioning of voluntary health insurance and insufficient promotion of their services;

- A small number of voluntary health insurance packages;

- Lack of correlation between mandatory and voluntary forms of health insurance and public and private health institutions;

- Unfair competition of private health care institutions and other institutions.

Given the importance of achieving a larger insurance coverage as a part of health improvement reform, it is necessary to monitor expenditures on medical care services and the impact of voluntary insurance on consumers' protection (Barber \& Yao, 2011). While public health insurance should cover medically necessary health services, other types of insurance coverage are meant to be offered by private companies (Ward \& Johnson, 2013). However, lower income of citizens and the lack of education in this area may prevent them from purchasing voluntary insurance premiums. In order to promote private insurance coverage, many states defined certain obligatory insurance types, "such as employment-connected health insurance, which obligate employers to insure their employees" (Battistella\& Burchfield, 2000; Monheit\&Vistnes, 2008; Guy et al., 2012; Karuppan, 2014). Despite the fact that private and public insurance are often observed as extremes, they, in fact, overlap as a result of government intervention in the insurance market. So far, private insurance is dominant in developed countries with organized regulatory schemes. Besides the incentive for 
growth of private insurance market, such regulations and public intervention are necessary due to a number of factors, including the need to regulate the operation of financial institutions in general, prevent market failures, preserve the health of citizens and timely address various health risks, etc. (Roberts, 2004).

\section{Relationship between insurance companies and private healthcare institutions}

There is a wide range of relationships between insurance companies and private healthcare institutions. The so-called hybrid health management organizations, the vertically integrated framework of full cooperation, represent one extreme. These models of cooperation are operated through integration of private health care and health insurance organizations (Vargas et al., 2010). In such systems, consumer and physician data are commonly collected in order to perform better and detect and eliminate certain problems (Miller \&Luft, 2002; Mohammed et al., 2014). The appearance of such cooperatives is a result of more sophisticated consumers' requirements, consumers who are willing to change healthcare institutions or insurance companies if dissatisfied with services they receive. This possibility of losing customers makes health organizations respond to consumers' needs and preferences for better quality at reasonable costs (Thomson \& Dixon, 2004; DiCenzo\&Fronstin, 2008). Modern consumers are seeking information about various health insurance types and health care providers (Deloitte, 2008) in order to compare different options and make affiliation decisions (Becker \&Zweifel, 2008). In such cases, consumers choose certain organizations based on their evaluation of various attributes of the offer, such as: package of services, high quality of medical services, efficiency of service provision and a waiting period to receive healthcare services, politeness of medical and non-medical staff, family coverage, access to specialists, right to choose a doctor, etc. (Amaya et al., 2014). Based on the critical assessment of information about the quality, price and patient satisfaction, most consumers would, most probably, change the medical or insurance organization if not completely satisfied (de Jong et al.,2008; Lako et al., 2011). Fully integrated systems of healthcare institutions and insurance companies can prevent losing of consumers, as services provided this way are synergized, highly efficient and professional. Insurance companies can sell insurance packages that cover medical services of a certain private medical provider, which make them take care of consumers and develop longterm relationships, based on their complete satisfaction with the performances of a hybrid system.

But, such full cooperation is rare in practice, especially in developing countries. Insufficient development of the healthcare sector in Serbia has resulted in a weaker mutual cooperation of private health care institutions and insurance companies, no matter those insurance companies are participating in the total income of medical institutions by up to $35 \%$ per year (MediGroup,2013). As a matter of fact, in their cooperation, insurance companies play a dominant role because they are able to, by their sole discretion, determine which health care institutions they want in their cooperation network. This dominant role allows them to dictate the terms of cooperation, from financial (in addition to regular discounts they are allowed by healthcare institutions, they often request permanent special prices, which is legally impermissible), to the contractual clauses on the priority right when scheduling their policy holders, which is contrary to medical ethics. Despite these conditions, medical institutions agree to sign cooperation agreements, as they gain financial benefits from them, given a significant revenue they receive from the insured patients. In fact, cooperation with insurance companies is recognized as necessary especially in the initial period of establishing health institutions, because, without a necessary budget to invest in marketing activities, brand strength of insurance companies is the one that provides clients. Later, with the development of healthcare institutions and their positioning in the market, this interdependence can move in favour of health care institutions, so that the quality of packages of insurance companies will depend on whether a particular medical institution is in their joint network. Bearing in mind the tendency of grouping of health institutions in Serbia (the first private health platform "MediGroup" was formed during 2012 and 2013), it is expected that the position of private healthcare institutions will further improve, so the insurance companies must respect their demands more. In fact, some private institutions are already recognized for their quality (recognized experts, good equipment and excellent accommodation facilities), which is why insurance clients simply insist on medical services of a particular institution when purchasing insurance premiums. In addition, strengthening of the role of private health care institutions within an interdependent relationship with insurance companies is also reflected in the fact that health care institutions are beginning to deal with the provision of various services that are on the verge of services that are normally offered by insurance companies. By preparing for this situation and observing the practices of the Eastern European countries, which has resulted in several court proceedings between insurance companies and private health 
institutions, insurance companies in Serbia put pressure on the National Bank of Serbia to ban the sale of services that resemble insurance for all other institutions, except insurance companies. So far, they partly succeeded in doing that, since the Insurance Act introduced in January 2015 made acting of all legal entities and their representatives punishable (in financial sense or imprisonment) in case they are proved to be engaged in selling services that resemble insurance. This especially concerns private medical institutions, as they have already begun to offer this kind of service packages to customers, so reactions of insurance companies and legal authorities are now expected. In a way, healthcare organizations and insurance companies may turn into competitors for consumers, as they sell the same service packages. Although some consider that this competition may encourage good performance of both sides (Maarse et al., 2005; Chalkley\&Khalil, 2005), the fact is that opportunistic behaviour by any side will increase the consummation of financial resources without improving the health of the population. The necessity to introduce some sort of control mechanisms in this area and monitor their expected effects on health care has been discussed in literature (Scott \& Farrar, 2003; Marinoso\&Jelovac, 2003).

In order to avoid the situation of growing competition between private healthcare organizations and insurance companies in Serbia, it is important to address the key policy questions that should regulate the relationship between those subjects. Those key questions are the following:

- First, areas of acting of private healthcare institutions and insurance companies should be precisely determined and divided, so it would become clear which organization should be allowed to sell certain service packages. By making a clear, legally imposed framework of business activities, there would be no overlapping in courses of action, and, consequently, no need for competitive relations.

- It is important to notice to what extent private insurances are being encouraged, as a way of providing greater choice to consumers, to cooperate with a number of various private healthcare institutions that are expected to compete with discounts they allow to insurers. This represents an important issue in the Serbian market that should be regulated in order to enable fairer market relations.

- State institutions are obligated to define how much competition is good to be encouraged and how much cooperation should be encouraged among insurers and healthcare institutions.

- It is important to clearly determine how broadly private insurance coverage should be extended and how important consumers' choice and service customization are in order to meet the needs of different socio-economic groups.

- Finally, a highly sensitive and important issue is setting the medical and insurance service prices, as well as stipulate the ways in which business subjects within the network should share financial and other business risks (Sekhri\&Savedoff, 2006).

Providing legal answers to these key policy questions would significantly improve practice in the Serbian market and provide solid basis for further development of cooperative relationships between private healthcare institutions and insurance companies.

Conslusion

It is evident that, on a global level, great emphasis is being given to the provision of a sufficient quality of health care and implementation of a more efficient and better-formulated health reforms. One of the trends that occurs as a response to current market changes in developing countries is the expansion of private healthcare institutions. In order to meet sophisticated consumers' needs, healthcare institutions develop a wide range of relationships with insurance companies. This represents the tendency to move toward an integrated, patient-focused health approach and attract consumers who pay great attention to a qualitative dimension of healthcare services. Although the cooperation between these subjects in the private sector is more than desirable, in practice, there are many unsolved issues that prevent their full integration; moreover, make them more like competitors for market segments. This paper provides a theoretical basis for further, more detailed analyses of this field, which should be conducted in order to define adequate strategies for regulating the relations among business subjects in the health service market. Also, a comparative analysis of practices in this field in other countries would be of great importance, so some positive models could be used for the purpose of improvement of the current situation in the Serbian market. 


\section{REFERENCES}

[1] Amaya, J.L., Ruiz, F., Trujillo, A.J., \&Buttorff, C.(2014). Identifying barriers to move to better health coverage: preferences for health insurance benefits among the rural poor population in La Guajira, Colombia. International Journal of Health Planning and Management, DOI: 10.1002/hpm.

[2] Barber, S.L., Yao, L. (2011). Development and status of health insurance systems in China.International Journal of Health Planning and Management, 26, 339-356.

[3] Battistella,R.,\&Burchfield, D. (2000). The future of employment-based health insurance, Journal of Healthcare Management,45(1), 46-57.

[4] Becker, K., \&Zweifel, P. (2008). Age and choice in health insurance. Patient, 1, 27-40.

[5] Borghi, J., Storeng, K., \&Filippi, V. (2008). Overview of the costs of obstetric care and the economic and social consequences for households. Studies in Health Services Organization \& Policy, 24, 23-46.

[6] Cannoodt, L., Mock, C., \&Bucagu, M. (2012). Identifying barriers to emergency care services, International Journal of Health Planning and Management, 27, e104-e120.

[7] Chalkley, M., \&Khalil, F. (2005). Third party purchasing of health services: patient choice and agency. Journal of Health Economics, 24, 1132-1153.

[8] Collins, T. (2006). The Georgian healthcare system: Is it reaching the WHO health system goals? International journal of health planning and management, 21, 297-312.

[9] de Jong, J., Van den Brink-Muinen, A., \&Groenewegen, P. (2008). The Dutch health insurance reform: Switching between insurers, a comparison between the general population and the chronically ill and disabled. BMC Health Services Research, 8(19), 58-66.

[10] Deloitte. (2008). 2008 Survey of health care consumers. Washington, DC: Deloitte Center for Health Solutions.

[11] DeltaGenerali.(2012). Annual Report for Serbian market.

[12] DiCenzo, J., \&Fronstin, P. (2008). Lessons from the evolution of $401(\mathrm{k})$ retirement plans for increased consumerism in health care: An application of behavioral research. Washington, DC: EBRI Employee Benefit Research Institute.

[13] Echebiri, V. C. (2014). The factors affecting Nigeria's success toward implementation of global public health priorities. Global Health Promotion,0(0), 1-6.

[14] Gery, P.G.Jr., Adams,E.K., \&Atherly, A. (2012). Public and private health insurance premiums: How do they affect the health insurance status of low-income childless adults? Inquiry, 49, 52-64.

[15] Gotsadze, G., Bennett, S., Ranson, K., \&Gzirishvili, D. (2005). Healthcare-seeking behaviorand out- ofpocketpaymentsinTbilisi,Georgia.OxfordUniversityPressinAssociationwithLondon School of Hygiene and Tropical Medicine: Oxford, UK.

[16] Griffin, P.M.,Lee, H.,Scherrer, C.,\& Swann, Julie L.(2014).Balancing investments in federally qualified health centers and Medicaid for improved access and coverage in Pennsylvania, Health Care Management Science, 17, 348-364

[17] Gulbiye, Y.Y., \&Ugurluoglu, E. (2011). Can Turkey's general health insurance system achieve universal coverage? International Journal of Health Planning and Management, 26, 282-295.

[18] Institute of Public Health of Serbia "Dr Milan JovanovicBatut “. (2013). Annual report.

[19] Institute of Public Health of Serbia "Dr Milan JovanovicBatut “. (2012). Annual report.

[20] Jofre-Bonet, M.(2000). Public health care and private insurance demand: The waiting time as a link. Health Care Management Science, 3, 51-71.

[21] Johnston, D.J. (2004). Increasing value formoneyin healthsystems. European Journal of Health Economy, 5, 91-94.

[22] Jost, T. S. (2001). Private or public approaches to insuring the uninsured: lessons from inter- national experience with private insurance. NY University of Law Review, 76(2), 419-492.

[23] Karuppan, C. M. (2014).Employer-based coverage and medical travel options: Lessons for healthcare managers.Journal of Healthcare Management, 59(3), 210-222.

[24] Kotzian,P. (2008). Control and performance of health care systems. A comparative analysis of 19 OECD countries. International Journal of Health Planning and Management, 23, 235-257.

[25] Kutzin, J. (2001). A descriptive framework for country-level analysis of health care financing arrangements. Health Policy, 56(3), 171-204.

[26] Lako, C. J.,Rosenau, P.,\&Daw, C. (2011). Switching health insurance plans: Results from a health survey. Health Care Anal,19, 312-328.

[27] Maarse, H., Paulus, A., \&Kuiper, G. (2005). Supervision in social health insurance: a four country study. Health Policy, 71, 333-346. 
[28] Marinoso, B.G., \&Jelovac, I. (2003). GP's payment contracts and their referral practice. Journal of Health Economics, 22, 617-635.

[29] MediGroup. (2013). Annual financial report.

[30] Miller, R. H., \&Luft, H. S. (2002). HMO plan performance update: An analysis of the literature, 1997-2001. Health Affairs, 21, 63-86.

[31] Monheit,A. C., \&Vistnes,J. P. (2008). Health insurance enrollment decisions: Preferences for coverage, worker sorting and insurance take-up. Inquiry, 45, 153-167.

[32] Murray, C.J.L., \&Frenk, J. (2001). World health report 2000: a step towards evidence-based health policy. Lancet, 357, 1698-1700.

[33] National Bank of Serbia. (2013). Report on the insurance sector.

[34] Raminashvili, D., Bakhturidze, G., Zarnadze, I., Peikrishvili, N., \&Bull, T. (2014). Promoting health in Georgia. Global Health Promotion, 21(1), 5-12.

[35] Roberts, M. J. (2004). Getting health reform right: A guide to improving performance and equity. Oxford University Press: Oxford, New York.

[36] Savedoff, W. (2004). Is there a case for social insurance? Health Policy Plan, 19(3), 183-184.

[37] Scandinavian Care. (2006). Improvement of hospital governance/management and strategic planning. Tbilisi, Georgia: Georgia Structural Reform Support Project.

[38] Schaapveld, K., \&Rhodes, G. (2004). Observations on health financing reform in the Republic of Georgia, 1996-2002. Applied Health Economics Health Policy, 3(3), 127-132.

[39] Scott, A., \&Farrar, S. (2003). Incentives in health care. In Advances in Health Economics, Scott A, Maynard A, Elliott R (eds). Wiley: Chichester, 77-98.

[40] Sekhri, N., \&Savedoff, W. D. (2006).Regulating private health insurance to serve the public interest: Policy issues for developing countries. International Journal of Health Planning and Management, 21, 357392.

[41] Sekhri, N., \&Savedoff, W. D. (2005). Privatehealthinsurance:Implications fordevelopingcountries. Bulletin of the World Health Organization, 83(2), 127-134.

[42] Shafiu, M., Souares, A., Bermejo, J. L.,Babale, S. M.,Sauerborn, R., \&Dong, H. (2014). Satisfaction with the level and type of resource use of a health insurance scheme in Nigeria: Health management organizations' perspectives. International Journal of Health Planning and Management, 29, e309-e328.

[43] Smith, D. G. (2008). What's in it for you? Understanding the plight of the uninsured.Journal of Healthcare Management,53(3), 146-168.

[44] Song, P. H., \&Smith, D. G. (2007). Financial preconditions for successful community initiatives for the uninsured.Journal of Healthcare Management, 52(6), 411-424.

[45] Thomson, S., \& Dixon, A. (2004). Choices in health care: The European experience. Euro Observer, 6(4), 1-5.

[46] Vargas, I., Vazquez, M. L., Mogollon-Perez, A. S., \&Unger, J-P. (2010). Barriers of access to care in a managed competition model: lessons from Colombia. BMC Health Services Research,10, 297.

[47] Ward, A., \&Johnson,P. J. (2013). Necessary health care and basic needs: Health insurance plans and essential benefits. Health Care Anal,21, 355-371.

[48] Zuckerman, A. M. (2014). Successful strategic planning for a reformed delivery system. Journal of Healthcare Management, 58, 168 - 172. 


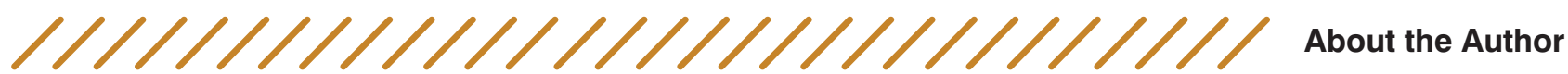

\section{Željko Jović \\ Medi Group, Milutina Milankovića 3, Belgrade, Serbia z.jovic@medigroup.rs}

ŽeljkoJović was born in 1973 In Valjevo, Serbia. He graduated from the Military Academy in Belgrade in 1996 and received his master's degree at the Faculty of Security, Belgrade in in 2013. He currently holds the position of Sales director at "Medi Group", the first private healthcare platform in Serbia. He is the author of several articles in the field of marketing in healthcare published in journals and conference proceedings in this field.

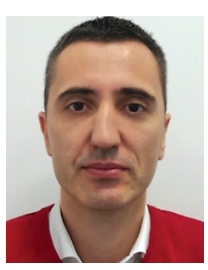

Jelena Cvijović

University of Belgrade, Faculty of Organizational Sciences, Serbia jelencvijovic85@gmail.com

Jelena Cvijović is a doctoral student at the Faculty of Organizational Sciences, University of Belgrade. The areas of her scientific interest are: marketing communications, indirect advertising, social marketing and consumer behaviour. She has so far published more than twenty research papers in international and national journals and conference proceedings. 